\title{
Measuring Systemic Risk Across Financial Market Infrastructures
}

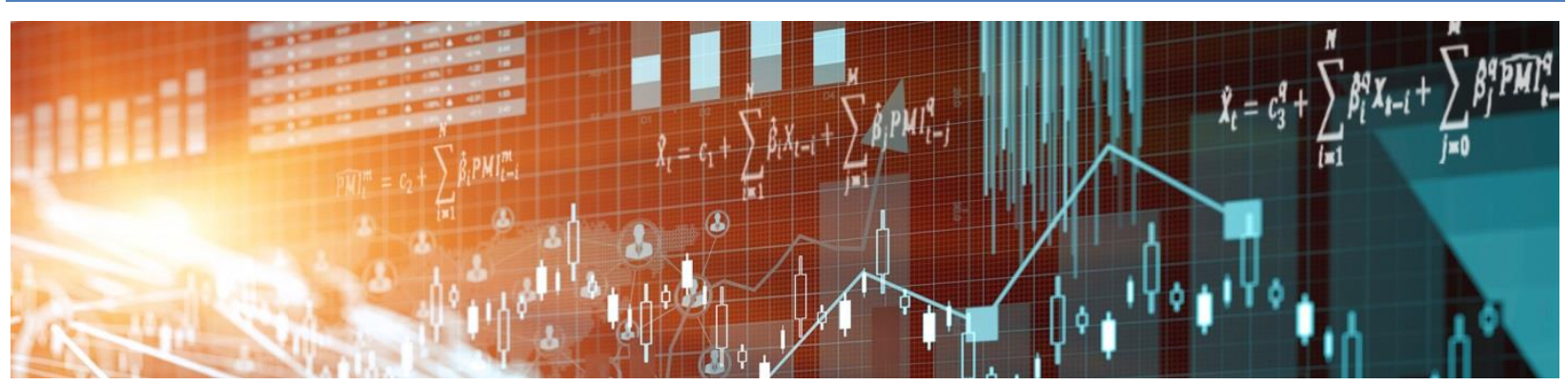

by Fuchun Li and Héctor Pérez Saiz 
Bank of Canada Staff Working Paper 2016-10

March 2016

\title{
Measuring Systemic Risk Across Financial Market Infrastructures
}

\author{
by \\ Fuchun Li and Héctor Pérez Saiz \\ Financial Stability Department \\ Bank of Canada \\ Ottawa, Ontario, Canada K1A 0G9 \\ lifu@bankofcanada.ca \\ perh@bankofcanada.ca
}




\section{Acknowledgements}

We thank Omar Abdelrahman and Blair Williams for excellent research assistance. We also want to thank Jason Allen, Carol Brigham, Franscesca Carapella, James Chapman, Peter Christoffersen, Jorge Cruz, Paul Glasserman, Kari Kemppainen, Wade McMahon, Paul Miller, Miguel Molico, Alexandre Ruest, Varya Taylor, Maarten van Oordt and Gabriel Xerri for helpful discussions. We benefited from comments from participants in seminar series/conferences at the Bank of Canada, the Bank of Finland, the 2015 Bundesbank Conference on Payments and Settlement, and the 2015 Cleveland Fed/OFR Financial Stability Conference. 


\begin{abstract}
We measure systemic risk in the network of financial market infrastructures (FMIs) as the probability that two or more FMIs have a large credit risk exposure to the same FMI participant. We construct indicators of credit risk exposures in three main Canadian FMls during the period 2007-11 and use extreme value methods to estimate this probability. We find large differences in the contribution to systemic risk across participants. We also find that when participants are in financial distress, they tend to create large credit exposures in two or more FMls. Our results suggest that an appropriate oversight of FMIs may benefit from an in-depth system-wide analysis, which may have useful implications for the macroprudential regulation of the financial system.
\end{abstract}

JEL classification: 621, G23, C58

Bank classification: Payment clearing and settlement systems; Financial stability;

Econometric and statistical methods

\title{
Résumé
}

Nous mesurons le risque systémique dans le réseau des infrastructures de marchés financiers (IMF) en fonction de la probabilité que deux IMF ou plus aient une forte exposition au risque de crédit à l'égard d'un même participant. Pour ce faire, nous construisons des indicateurs des expositions au risque de crédit présentes dans trois grandes IMF canadiennes pour la période de 2007 à 2011, et avons recours à des méthodes fondées sur la théorie des valeurs extrêmes pour estimer cette probabilité. Les participants ne sont pas une source de risque systémique au même degré : de ce point de vue, nous observons d'importantes différences entre eux. Nous constatons également que lorsqu'ils connaissent des difficultés financières, les participants ont tendance à accroître l'exposition au risque de crédit dans deux IMF ou plus. Nos résultats indiquent qu'il serait bon, pour une surveillance appropriée des IMF, d'effectuer une analyse approfondie de l'ensemble du réseau, analyse qui pourrait avoir son utilité pour la réglementation macroprudentielle du système financier.

Classification JEL : G21, G23, C58

Classification de la Banque : Systèmes de compensation et de règlement des paiements; Stabilité financière; Méthodes économétriques et statistiques 


\section{Non-Technical Summary}

Financial market infrastructures (FMIs) are at the heart of every country's financial system. They facilitate the clearing, settling or recording of payments, securities, derivatives or other financial transactions among participating entities. They allow consumers and firms to safely and efficiently purchase goods and services, make financial investments and transfer funds. Because of their systemic importance, FMIs are regulated and overseen by central banks and other authorities. However, relatively little is known about the risks that participants can create in the network of FMIs. Our article is one of the first attempts to measure these risks.

We measure systemic risk in the network of FMIs, defining it as the probability that two or more FMIs have a large credit risk exposure to the same participant. We first construct indicators of credit risk exposures from the point of view of the following three main Canadian FMIs: the Large Value Transfer System (LVTS), the Canadian Derivatives Clearing Service (CDCS) and CDSX (owned and operated by Clearing and Depository Services Inc.). These FMIs have a leading role in the clearing and settlement of cash payments, derivatives and other securities.

We define credit risk exposure as the payment obligation that a participant has with the FMI at the end of the day. We consider both gross payment obligations and net payment obligations (net of any collateral pledged by the participant). We calculate these indicators using a database with detailed daily data on prices, positions margins and other types of collateral for every FMI's participant for the period 2007-11.

Based on these credit risk indicators, we use extreme value methods to estimate the probability of the tail event that two or more FMIs have a large credit risk exposure to the same participant. We also estimate the conditional probability that one or more FMI has a large credit risk exposure to a participant, conditional on another FMI having a large exposure to the same participant. These conditional probabilities provide useful information about the systemic risk contribution of one or more FMIs to another FMI by a participant. To the best of our knowledge, our article is the first to propose a measure of systemic risk in the network of FMIs that is based on the existence of participant-based interdependencies between FMIs.

We find a rich set of results with interesting implications. We find large differences in systemic risk measures across participants. We then re-estimate these probabilities by conditioning on the participant being close to financial distress. We use stock returns as a measure of financial distress. On average, we find that participants that are more likely to be in financial distress contribute more to systemic risk in the network of FMIs.

Our research contributes to the literature on systemic risk by measuring participant-based interdependencies between FMIs, which arise from the activities of one participant in two or more FMIs. Previous analysis has mainly considered dependencies between FMIs due to services that are provided by one FMI and used by other FMIs.

Our methodology has direct implications for better understanding financial stress across FMIs. FMIs are typically required to have sufficient pre-pledged collateral/funding available to cover a default situation in every FMI and thus mitigate the potential for systemic risk across FMIs. However, the default of a participant with a large exposure in two or more FMIs is a very stressful event, and current stress tests used in FMIs typically do not consider this scenario. Our paper provides a methodology for better understanding risks in the network of FMIs.

These results may be useful for regulators and policy-makers. Currently, there is a set of initiatives promoted and being implemented by central banks and other international organizations that are designed to improve the safety and soundness of FMIs as key elements in controlling systemic risk in the financial system. Our work could have important implications for the appropriate macroprudential regulation of the financial system. 


\section{Introduction}

Financial market infrastructures (FMIs) are at the heart of every country's financial system. They facilitate the clearing, settling or recording of payments, securities, derivatives or other financial transactions among participating entities. They allow consumers and firms to safely and efficiently purchase goods and services, make financial investments and transfer funds. Because of their systemic importance, FMIs are regulated and overseen by central banks and other authorities. However, relatively little is known about the risks that participants can create in the network of FMIs. Our article is one of the first attempts to measure these risks.

We measure systemic risk in the network of FMIs, defining it as the probability that two or more FMIs have a large credit risk exposure to the same participant. We first construct indicators of credit risk exposures from the point of view of the following three main Canadian FMIs: the Large Value Transfer System (LVTS), the Canadian Derivatives Clearing Service (CDCS) and CDSX (owned and operated by Clearing and Depository Services Inc.). These FMIs have a leading role in the clearing and settlement of cash payments, derivatives and other securities 11 We define credit risk exposure as the payment obligation that a participant has with an FMI at the end of the day. We consider both gross payment obligations and net payment obligations (net of any collateral pledged by the participant). We calculate these indicators using a database with detailed daily data on prices, positions, margins and other types of collateral for every FMI's participant for the period 2007-11.

Based on these credit risk indicators, we use extreme value methods to estimate the probability of the tail event that two or more FMIs have a large credit risk exposure to the same participant. We also estimate the conditional probability that one or more FMI has a large credit risk exposure to a participant, conditional on another FMI having a large exposure to the same participant. These conditional probabilities provide useful information about the systemic risk contribution of one or more FMIs to another FMI by a participant. Authors such as Lehar (2005), Segoviano et al. (2009), Gravelle and Li (2013), and Adrian and Brunnermeier (2015), among others, have proposed measures of the systemic importance of a financial institution or group of financial insti-

\footnotetext{
${ }^{1}$ The three FMIs have been designated as "systemically important" by the Payment Clearing and Settlement Act because they have the potential to pose systemic risk to Canada's financial system.
} 
tutions in the financial system. To the best of our knowledge, our paper is the first to propose a measure of systemic risk in the network of FMIs that is based on the existence of participant-based interdependencies between FMIs.

The detailed database we compiled allows us to find a rich set of results with interesting implications. First, when considering a set of seven large participants of all three FMIs, we find large differences in systemic risk measures across participants, and we find that three participants have, on average, a larger contribution to systemic risk than the other participants. We then re-estimate these probabilities by conditioning on the participant being close to financial distress (crash, failure or collapse). We use stock returns as a measure of financial distress. On average, we find that participants that are more likely to be in financial distress contribute more to systemic risk in the network of FMIs.

Our research contributes to the literature on systemic risk by measuring participant-based interdependencies between FMIs, which arise from the activities of one participant in two or more FMIs (BIS, 2008). Previous analysis has mainly considered dependencies between FMIs due to services that are provided by one FMI and used by other FMIs. These dependencies can be important. For instance, collateral for the LVTS is pledged through CDSX, whereas CDSX funds are settled at the end of the day in the LVTS. CDCS relies operationally on CDSX and the LVTS for margin requirements and cash-settlement, respectively.

Our methodology has direct implications for better understanding financial stress across FMIs. FMIs are typically required to have sufficient pre-pledged collateral/funding available to cover a default situation in every FMI and thus mitigate the potential for systemic risk across FMIs. However, the default of a participant with a large exposure in two or more FMIs is a very stressful event for the network of FMIs, and current stress tests used in FMIs typically do not consider this scenario 2 Under some circumstances, liquidity and market risks in such a situation could be substantial, and there would be significant stress and uncertainty in the market that could affect participants across systems. Non-defaulting participants may have to use their own resources to cover this obligation in every FMI. This could create additional stress in all participants and FMIs,

\footnotetext{
${ }^{2}$ See, for instance, OFR (2015), page 30: "A Global Systemically Important Bank (G-SIB's) default could cause a CCP default and possible strain [for] multiple CCPs at once, a scenario that current CCP stress tests may fail to capture."
} 
and it could potentially create defaults of participants or possibly FMIs, making this initial default a systemic event. Regardless of the probability of this chain of events occurring in a future financial crisis, our paper provides a methodology for better understanding risks in the network of FMIs.

These results may be useful for regulators and policy-makers. Currently, there is a set of initiatives promoted and being implemented by central banks and other international organizations that are designed to improve the safety and soundness of FMIs as key elements in controlling systemic risk in the financial system $3^{3}$ Our work could have important implications for the appropriate macroprudential regulation of the financial system 4

The safety and soundness of FMIs has been at the center of the policy interest in most central banks for several decades. Much of the literature focuses on the study of large-value payment systems, considering topics such as network topology (Embree and Roberts, 2009; Bech et al. 2010; Chapman et al. 2011) or efficiency effects (Allen et al., 2015). The empirical work on other FMIs is more recent, mainly due to limitations on data availability ${ }^{5}$ Some recent studies use proprietary data from central counterparties (CCPs) to study issues such as systemic risk within a CCP (Cruz Lopez et al., 2013; Jones and Pérignon, 2013) or the effects of central clearing on collateral demand and prices (Duffie et al. 2015 ; Menkveld et al., 2015).

One of the first articles to study the interactions between FMIs is Renault et al. (2007). There is also some recent work that studies the links between different types of FMIs from a network perspective (León and Pérez, 2014, León et al., 2014). Anderson et al. (2013) and Mägerle and Nellen (2015) use credit risk exposures to study the degree of efficiency of different linked CCP structures. As well, Embree and Millar (2008) study the risks associated with interactions between a payment system and a securities settlement system.

With the recent financial crisis, there has been a greater interest in applying extreme value

\footnotetext{
${ }^{3}$ One clear example is the Principles for Financial Market Infrastructures (PFMIs) from the CPMI-IOSCO (BIS, 2012 that serve as important risk management principles for systemically important FMIs. Among other issues, the PFMIs discuss the importance of measuring, monitoring and managing credit risk exposures, as well as risks related to links between FMIs (see also BIS, 2008).

${ }^{4}$ For instance, a participant could be classified as individually systemic because of its large contribution to systemic risk in the network of FMIs, and therefore it could receive special attention from regulators, since a default by the participant could potentially create significant stress in the network of FMIs.

${ }^{5}$ Because payment systems are highly connected to the daily operations of central banks and the implementation of monetary policy, there is usually more data available and research conducted related to these systems.
} 
theory methods, pioneered by Fisher and Tippett (1928) to measure the systemic importance of financial institutions. See Poon et al. (2004), Hartmann et al. (2005), Acharya et al. (2010) or Gravelle and Li (2013), to cite a few. These methods have been proven to be useful for measuring tail events in the financial industry. To the best of our knowledge, ours is the first application of extreme value methods to measure systemic risk in the network of FMIs.

The paper proceeds as follows. In the next section we describe the methodology used to estimate systemic risk across FMIs. Section 3 describes the industry and proposes a set of indicators to estimate credit risk across FMIs. Section 4 presents the empirical results. Section 5 concludes.

\section{Estimating systemic risk across FMIs}

\subsection{Systemic risk across FMIs}

Following work by the Bank for International Settlements (BIS, 2008), there exist three major types of dependencies between FMIs: (i) system-based dependencies, which arise from direct links between FMIs (FMI-based interdependencies); (ii) environmental dependencies, which refer to the dependence of FMIs on common third-party services or infrastructure providers; and (iii) participant-based dependencies, which refer to the links between two or more FMIs through a common participant. In our paper, we focus on number (iii), but we concur with the importance of the other two. The type of link that we consider is particularly relevant for Canada because the financial industry is concentrated in a small number of large financial institutions. The default of a large participant could create significant stress in the FMIs, and it could potentially create additional stress on the surviving participants.

We classify exposures from the point of view of their type. BIS (2012) provides definitions of credit risk, liquidity risk, operational risk and other types of risk. In our paper, we focus on credit risk, which is defined as "the risk that a counterparty will be unable to meet fully its financial obligations when due or at any time in the future" (see Principles for Financial Market Infrastructures, page 19) 6 We measure credit risk as the end-of-day payment obligation that a participant

\footnotetext{
${ }^{6}$ Liquidity risk is adequately managed by FMIs having sufficient liquid resources to effect the settlement of payment obligations with a high degree of confidence. Operational risk is managed by FMIs setting high rates of availability
} 
has to the FMI. We consider both gross payment obligations and net payment obligations (net of any collateral pledged by the participant with the FMI).

Credit risk exposures can be classified from the point of view of the entity that is exposed. There is a two-sided relationship between every FMI and every participant, and the risks faced by the FMI or the participant are two sides of the same coin. For instance, a participant is exposed to the default/distress of the FMI or the FMI participants, because in case of a default of one participant, the obligations with the surviving participants may not be fulfilled by the FMI. In our paper, we focus on the exposure of an FMI to the participant: The FMI/surviving participants will face distress as a result of a participant in default/distress. For instance, in Figure 1 we show a simple case where two participants are members of all three FMIs. A default of participant 1 could be a very stressful event for participant 2 if it needs to use its own resources to cover this default in every FMI.

We denote by $E_{j}^{b}$ the credit risk exposure associated with participant $b$ in FMI $j$. This credit risk exposure is measured as the end-of-day payment obligation in the FMI, and we assume the following sign convention:

$$
\begin{aligned}
& E_{j}^{b} \geq 0 \text { : if FMI } j \text { "owes" } E_{j}^{b} \text { to participant } b, \text { and } \\
& E_{j}^{b}<0 \text { : if participant } b \text { "owes" } E_{j}^{b} \text { to FMI } j
\end{aligned}
$$

We are interested in situations where FMI $j$ is exposed to participant $b$, i.e., $E_{j}^{b}<0$. A situation where $E_{j}^{b} \geq 0$ but relatively close to 0 is also interesting because small deviations of asset prices could easily reverse the sign of $E_{j}^{b}$ for large participants $]^{7}$ Therefore, we are interested in the case where $E_{j}^{b} \leq K_{j}^{b}$, where $K_{j}^{b}$ is a relatively low threshold. In practice, the threshold $K_{j}^{b}$ is defined as a quantile (such as the $5 \%$-quantile, i.e., $\left.\operatorname{Pr}\left[E_{j}^{b} \leq Q_{j}^{b}\right]=0.05\right)$ in order to measure exposures in relative terms. Figure (2) schematically shows the distributions of gross and net exposures with

(such as $99.99 \%$ ) and a low number of incidents/outages in their systems. For an example, see the annual reports of the Canadian Payments Association.

${ }^{7}$ Because some participants are much larger than others, the order of magnitude of the exposures varies across participants. Therefore, it is important to consider relative levels of exposures rather than absolute levels. For instance, if we consider a threshold of $\$ 500$ million, this threshold can be too high for a small provincial participant, but too low a threshold for a large global participant because small deviations of asset prices could significantly change these exposures for the large participant. 
the sign convention considered. It also shows the threshold $K_{j}^{b}$ and the relationship between gross exposures and net exposures. Net exposures are calculated by adding the collateral pledged to the gross exposures. Hence, the distribution of net exposures is shifted to the right by an amount equal to the collateral pledged.

For given $E_{j}^{b}$ and a quantile threshold $Q_{j}^{b}$ for each of the three systems considered, we measure systemic risk in the network of FMIs, defined as the probability that two or more FMIs have a large credit risk exposure to the same FMI participant. We study four cases. First, we consider the joint probability that three FMIs simultaneously have a large credit risk exposure:

$$
\operatorname{Pr}\left[E_{1}^{b} \leq Q_{1}^{b}, E_{2}^{b} \leq Q_{2}^{b}, E_{3}^{b} \leq Q_{3}^{b}\right]
$$

Then, we consider three cases for the joint probability that two FMIs simultaneously have a large credit risk exposure (CDCS and CDSX, CDCS and LVTS, CDSX and LVTS),

$$
\operatorname{Pr}\left[E_{j}^{b} \leq Q_{j}^{b}, E_{k}^{b} \leq Q_{k}^{b}\right] \text {, for } j, k \in\{1,2,3\}, j \neq k
$$

We are also interested in studying conditional probabilities for combinations of FMIs such as

$$
\operatorname{Pr}\left[E_{j}^{b} \leq Q_{j}^{b} \mid E_{k}^{b} \leq Q_{k}^{b}, E_{l}^{b} \leq Q_{l}^{b}\right], \text { or } \operatorname{Pr}\left[E_{j}^{b} \leq Q_{j}^{b} \mid E_{k}^{b} \leq Q_{k}^{b}\right] \text {, for } j, k, l \in\{1,2,3\}, j \neq k \neq l \text {. }
$$

These conditional probabilities provide useful information on the systemic risk contribution of one or more FMIs to another FMI by a participant. This systemic risk measure differs from an individual FMI's own risk measure related to participant $b$ (value-at-risk) as it gives information about the part of systemic risk that can be attributed to another system.

Extreme value methods have proved to be an effective way to calculate probabilities of tail events in the financial system (Gravelle and Li, 2013). To the best of our knowledge, these methods have not been used to estimate systemic risk in the network of FMIs. In Appendix A we show how we use these methods to calculate the joint and conditional probability in Eqs. (3), (4) and (5). 


\subsection{Systemic risk across FMIs and participants in financial distress}

The probabilities in Eqs. (3), (4) and (5) do not take into account the financial distress of a participant. Participants in these systems are typically large financial institutions with significant activity in other markets such as retail and wholesale banking or money markets, and usually have global operations. The financial distress of a participant can be considered as an exogenous event triggered by conditions not necessarily related to its operations in the FMIs. Lehman Brothers, for instance, filed for bankruptcy on September 15, 2008 due to its large exposures in the subprime mortgage market, and this default created significant financial stress in the CCPs where Lehman was a participant (LCH.Clearnet in the U.K. and DTCC in the U.S.). ${ }^{8}$ We are interested in estimating systemic risk in the network of FMIs conditional on the financial distress of a participant. If a participant in financial distress creates large systemic risk in the network of FMIs, then regulators should be particularly concerned about it.

A participant $b$ is defined to be in financial distress (crash, failure or collapse) if its stock return, $S^{b}$, falls below a given crisis level $\left(Q_{S}^{b}\right)$ at a given tail probability $p$, i.e., $P\left[S^{b} \leq Q_{S}^{b}\right]=p 9^{9}$ Ideally, detailed balance sheet data on assets and liabilities should be used to construct measures of financial distress for participants, but balance sheet data usually have a low frequency and cannot be combined with the daily FMI exposure data. The stock returns have two major advantages. First, they can be updated in a more timely fashion. Second, they are usually forward-looking, because price movements reflect changes in market anticipation of the future performance of participants.

We denote by $S^{b}$ the first difference of log daily prices in participant $b$ stock, $P^{b}(t)$ :

$$
S^{b}=\log \left(P^{b}(t)\right)-\log \left(P^{b}(t-1)\right)
$$

Table 1 shows statistics for the distribution of log daily stock returns (common equity) for all FMI participants with publicly traded stock for the years 2004-11. There is substantial variation in stock

\footnotetext{
${ }^{8}$ See Monnet et al. $(2010)$.

${ }^{9}$ There are other candidates that could be used to measure financial distress, such as credit default swaps (CDS). However, CDS for Canadian financial institutions are typically traded over-the-counter, and therefore it is an opaque and not very liquid market (Reid, 2005). The choice of bank equity prices for measuring the credit risk of banks may be motivated by the option-theoretic framework toward default of Merton (1974). Merton's approach has become the cornerstone of a large body of approaches for quantifying credit risk and modeling credit rating.
} 
returns, with a maximum daily value of 0.32 and a minimum of -0.89 . 5\%-quantiles are negative in all years with an average value of -0.059. Returns for the years 2007, 2008 and 2011 are, on average, the lowest for the sample.

\section{Table 1 here}

We calculate probabilities in Eqs. (3), (4) and (5) by conditioning on the event that the participant is in financial distress, which occurs if the stock price falls below the threshold $Q_{S}^{b}$, which happens with probability $p$.

We estimate the joint probability that three FMIs simultaneously have a large credit risk exposure conditional on the event that the participant is in financial distress,

$$
P\left[E_{1}^{b} \leq Q_{1}^{b}, E_{2}^{b} \leq Q_{2}^{b}, E_{3}^{b} \leq Q_{3}^{b} \mid S^{b} \leq Q_{S}^{b}\right]
$$

In order to measure the increase in the contribution to systemic risk conditional on the participant being in financial distress, we use the difference between conditional and unconditional probabilities:

$$
\Delta_{b}\left(E_{1}^{b}, E_{2}^{b}, E_{3}^{b}\right)=P\left[E_{1}^{b} \leq Q_{1}^{b}, E_{2}^{b} \leq Q_{2}^{b}, E_{3}^{b} \leq Q_{3}^{b} \mid S^{b} \leq Q_{S}^{b}\right]-P\left[E_{1}^{b} \leq Q_{1}^{b}, E_{2}^{b} \leq Q_{2}^{b}, E_{3}^{b} \leq Q_{3}^{b}\right] .
$$

If $\Delta_{b}<0$, participants that are in financial distress contribute less to systemic risk in the network of FMIs. On the other hand, if $\Delta_{b}>0$, participants that are in financial distress contribute more to systemic risk in the network of FMIs. This difference is calculated in a similar way using conditional probabilities, as in Eq. (5).

\section{Credit risk exposures across FMIs}

\subsection{Credit risk exposures in CDCS}

CDCS is the clearing system operated by the Canadian Derivatives Clearing Corporation (CDCC), a subsidiary of TMX Group. CDCS provides a CCP service for all equity derivatives, index derivatives 
and interest rate derivatives traded on the Montréal Exchange (MX) ${ }^{10}$ Additionally, CDCS provides a clearing service for over-the-counter (OTC) equity options. The great majority of the trading of derivatives cleared in CDCS are originated on the MX.

The exposure of CDCS to a clearing member is equal to the payment obligation of the member due to the realized profits and losses $(\mathrm{P} \& \mathrm{~L})$ of its portfolio of derivatives cleared by CDCS. A clearing member $b$ has a long $\left(L_{s, t}^{b}\right)$ or short $\left(S_{s, t}^{b}\right)$ position on a given security $s$ in day $t$. Depending on having a long or short position and the changes in the price $P_{s, t}^{b}$ of the security, the end-of-day realized losses (variation margin) for participant $b$ is equal to

$$
\begin{aligned}
& V_{s, t}^{b}=L_{s, t}^{b}\left(P_{s, t}^{b}-P_{s, t-1}^{b}\right) \text { or } \\
& V_{s, t}^{b}=-S_{s, t}^{b}\left(P_{j, t}^{b}-P_{s, t-1}^{b}\right),
\end{aligned}
$$

where we use the following sign convention: $V_{s, t}^{b}>0$ if participant $b$ has a profit with security $s$, and $V_{s, t}^{b}<0$ if it has a loss. Figure 3 shows an example of price variation of a 10-year Government of Canada Bond Future on November 18, 2008.

Using the total portfolio of derivatives, we can calculate the aggregate losses of the participant $b$ in period $t$ :

$$
V_{t}^{b}=\sum_{s} V_{s, t}^{b}
$$

We can define the gross exposure of participant $b$ in period $t$ as the sum of all $\mathrm{P} \& \mathrm{~L}$ in the portfolio,

$$
E_{C D C S, G r o s s}^{b, t} \equiv V_{t}^{b}
$$

A measure of net exposure can be generated using the total collateral pledged by the clearing member. Clearing members pledge initial margins ${ }^{11}$ and if there is a default in period $t$, the CCP

\footnotetext{
${ }^{10}$ To control credit risk, CCPs use a legal instrument called novation. When the CCP novates the financial contract between two parties, it becomes the buyer to every seller and the seller to every buyer in the contract. CCPs also set risk controls (initial margins, default fund, etc.) to ensure that if a participant defaults, obligations between participants will be met under extreme but plausible stress scenarios.

${ }^{11}$ Typically, initial margins $B_{b, t-1}$ are set using some (value-at-risk) VaR methodology,

$$
\operatorname{Pr}\left(V_{b, t} \leq-B_{b, t-1}\right)=\alpha,
$$
}

where $\alpha=0.01$ or lower. 
can use the initial margin pledged at the end of the previous day to cover the losses. There is a wellestablished loss-allocation method to cover these losses; this is typically named "the waterfall."12 We assume that net losses are obtained after considering the initial margin and the default fund of the participant; we do not consider other mechanisms that mutualize losses in the waterfall (additional contributions of capital of the survivors, etc.). Net losses are typically absorbed by the surviving participants or by the CCP. Therefore, we can calculate the net exposure as:

$$
E_{C D C S, N e t}^{b, t} \equiv V_{b, t}+B_{b, t-1}+D F_{b, t-1},
$$

where $B_{b, t-1}$ is the total initial margin pledged in the previous period, and $D F_{b, t-1}$ is the total default fund.

\subsection{Credit risk exposures in CDSX}

CDSX is owned and operated by the Canadian Depository for Securities Limited (CDS), which in 2012 became a subsidiary of TMX Group. CDSX consists of a securities settlement system, a central securities depository and central counterparty services for eligible Canadian exchange-traded and over-the-counter equity trades (see McVanel, 2003).

Every participant $b$ has an end-of-day payment obligation, $P O_{b, t}$, which is the total amount of cash that the participant has to transfer to the FMI due to the net acquisition of securities (if $P O_{b, t} \geq 0$ ), or has to receive from the FMI due to the net sale (if $P O_{b, t}<0$ ). Therefore, we can define the gross exposure of participant $b$ as

$$
E_{C D S X, \text { Gross }}^{b, t} \equiv P O_{b, t} .
$$

CDSX has a loss-allocation procedure in the event that a participant is unable to meet its end-of-day payment obligation, backed in part by a pool of collateral that all extenders of credit maintain in accordance with the requirements set out in the CDSX rules. During the historical period considered in our sample, CDSX used a combination of defaulter-pays and survivor-pays risk

\footnotetext{
${ }^{12}$ See the International Swaps and Derivatives Association (2013) for more details.
} 
tools. The sum of all contributions to the pool by each participant was called the initial Aggregate Collateral Value (ACV). The value of the collateral in the initial ACV was set such that there was enough to cover the largest default among participants. Additional payment obligations not covered by the ACV must be covered with additional collateral contributions that increase the System Operating Cap (SOC). In any case, the payment obligation of an extender of credit with CDSX cannot be larger than the ACV or its SOC, whichever is less ${ }^{13}$

The collateral pool provides sufficient collateral to cover the payment obligation of the default of the largest extender of credit (at a $99 \%$ confidence interval). We consider this collateral, and also additional collateral pledged by participants, to calculate the net exposure of a participant $b$ in a day $t$, which is equal to

$$
E_{C D S X, N e t}^{b, t} \equiv P O_{b, t}+C_{b o l} .
$$

\subsection{Credit risk exposures in the LVTS}

The Large Value Transfer System (LVTS) ${ }^{14}$ is the Canadian electronic funds-transfer system that settles large-value and time-critical Canadian-dollar payments ${ }^{15}$ The LVTS provides two types of payment streams: Tranche 1 (T1) and Tranche 2 (T2). A participant can send a T1 payment as long as its net owing position is no greater than the collateral it has pledged in T1. If there is a default of a participant, its collateral is used to cover any net negative (debit) position in T1. For this reason, T1 payments are known as "defaulter-pays."

In T2, each participant voluntarily grants a bilateral credit limit (BCL) to every other participant. This line of credit is defined as the largest net amount that a participant can receive $\sqrt{16}$ In

\footnotetext{
${ }^{13}$ Starting in January 2015, the collateral pool was eliminated; therefore, in recent years defaulter-pays risk tools have been more predominant in CDSX.

${ }^{14}$ Other FMIs are overseen by the Bank of Canada, but we do not consider them in our analysis for a number of reasons. ACSS is the Canadian clearing system for small-value payments, and it is not considered to be of systemic importance. CLS Bank, located in New York (U.S.A.), is the global payment system for the settlement of foreign exchange transactions. The payment-versus-payment arrangement used in this system virtually eliminates all the credit risk, so we do not consider this FMI (see Kahn and Roberds, 2000, Miller and Northcott, 2002). LCH.Clearnet's SwapClear (in London, U.K.) is a global system for the central clearing of interest rate swaps and other over-the-counter interest rate derivatives denominated in multiple currencies, including the Canadian dollar.

${ }^{15}$ See Arjani and Mcvanel (2006) for a complete description of the system.

${ }^{16}$ Credit risk may not be a concern if FMI participants in financial distress are prevented from participating in these systems. In practice, opacity of financial markets and other frictions may prevent this. For instance, BCLs were approximately constant during the recent financial crisis, suggesting that many LVTS participants were not perceiving clearly the risk of their counterparties (Allen et al., 2011).
} 
addition, each participant has a multilateral net debit cap used for sending payments. Each LVTS participant pledges to the Bank of Canada an amount of collateral that depends on the largest BCL. If a participant fails to settle its final payment obligation, all losses not covered by the defaulting participant's collateral are allocated pro rata among the survivors based on their BCL with the defaulting participant. For this reason, T2 has been described as a "survivor-pays" system ${ }^{17}$

We calculate each participant's net position for the two tranches by adding together its T1 and T2 multilateral positions. At the end of the day, some participants may hold a net credit (positive) position, which means that they have received a net amount from the LVTS. Others hold a net debit (negative) position, which means that they have sent a net amount from the LVTS. For a given day $t$, we can calculate the gross exposure of participant $b$ by simply adding all payments received and sent to the system from the beginning of the day until the end of the day:

$$
E_{L V T S, G r o s s}^{b, t} \equiv \sum_{T 1, T 2} \sum_{\tilde{t} \leq E n d}\left(\text { received_payment }_{b, \widetilde{t}, t}-\text { sent_payment }_{b, \widetilde{t}, t}\right) .
$$

Figure 4 shows an example of the gross exposure of an LVTS participant on a representative day. Collateral is used to mitigate the impact of a participant's default. We assume that if there is a default, collateral pledged by each participant in T1 and T2 is used by the LVTS to cover the losses. Therefore, we define the net exposure of the LVTS to the default of participant $b$ in day $t$ as

$$
E_{L V T S, N e t}^{b, t} \equiv E_{L V T S, \text { Gross }}^{b, t}+\operatorname{Col}\left(T 1_{b, t}\right)+\operatorname{Col}\left(T 2_{b, t}\right)
$$

\section{Empirical results}

\subsection{Data sources}

We combine data from a variety of sources to calculate exposures across systems of different clearing participants. We have detailed data on the LVTS provided by the Canadian Payments Association

\footnotetext{
${ }^{17}$ Total collateral pledged is designed to cover a default of the largest participant in the LVTS. In the exceptionally remote event of multiple participant defaults, and where total collateral pledged is still not sufficient to cover the value of the final net debit positions of the defaulting participants, the Bank of Canada will provide a guarantee of settlement.
} 
(CPA). These data consist of all the daily payments sent and received by each LVTS participant, with the exact time of day, for each tranche. With this information, we can calculate the total debit/credit position at the end of the day. We also have the total collateral pledged by each participant each day to determine net exposures.

With regard to CDCS, we have long and short positions (i.e., the daily trading positions at market close) for the three-month Canadian bankers' acceptance futures (BAX), the 10-year Government of Canada Bond Futures (CGB) and the S\&P/TSX 60 Index Standard Futures (SXF) for all the clearing members active in the CDCS between 2 January 2003 and 31 March 2011. These are usually the most common instruments cleared in CDCS 18 Other instruments, such as options and OTC derivatives, are not available, but they represent a small fraction of all trading cleared. Clearing fund amounts (which do not often change between days) are available from January 2002 until March 2011. Initial margin amounts are available from January 2002 until end-2009. For additional information about this database, see Cruz Lopez et al. (2013). From CDSX, we have end-of-day settlement obligations and collateral pledged for each participant from March 2007 to end-2013.

We have several limitations in our data. Since the availability of data changes significantly across systems and years, we can only build gross exposures for the period 2007-11, and net exposures, only for the period 2007-09. Additionally, initial margins and the default fund obtained in CDCS are total margins pledged by each participant, and we assume that a fraction of them (50\%) correspond to the instruments we have 19

In order to jointly consider the different systems, we need to manually match the names of the different FMI participants across systems so that we have a single name that corresponds to the same participant across FMIs. Since the number of participants in Canadian FMIs is relatively low, this is a feasible task.

\footnotetext{
${ }^{18}$ We also have other futures instruments that are much less common. For example, MCX (Futures Contracts on Canada Carbon Dioxide Equivalents), or SCF (S\&P/TSX Composite Index Mini Futures).

${ }^{19}$ We have determined this number based on observed aggregated margins per security. A more careful analysis is left for future research and is conditional on data availability.
} 


\subsection{Exposures across systems and participants}

Table 2 shows statistics for different types of exposures across systems and participants. We use a sample of seven large participants (P1-P7) in all three systems, which accounts for a significant fraction of the Canadian financial industry. To provide a complete overview of the distribution of the exposures in all three FMIs, we use the sign convention as previously explained: A positive exposure means that the FMI owes money to the participant, and a negative exposure means that the participant owes money to the FMI. Net exposures are calculated by adding the collateral pledged to the gross exposures. Therefore, Table 2 provides information on the distribution of exposures, as shown schematically in Figure 2.

The first interesting finding is the differences in exposures across FMIs. We find that CDCS has lower exposures in absolute value compared with the other FMIs. Average gross and net exposures are of the order of tens of millions of dollars for CDCS. However, exposures in CDSX and the LVTS are in the order of billions of dollars. The portfolio of derivatives cleared in CDCS is small relative to other international CCPs. In addition, there was significant OTC trading not centrally cleared in the sample period considered ${ }^{20}$ This should not be used as an indication of the relative importance of every FMI. The three FMIs have been designated as "systemically important" by the Payment Clearing and Settlement Act because they have the potential to pose systemic risk to Canada's financial system. Since the three FMIs are comparable in terms of their perceived systemic importance, we treat them equally when we calculate the systemic risk probabilities in the next section.

In addition, we find that net exposures in CDSX show large positive numbers; meanwhile, gross exposures show large negative numbers. This is because the collateral scheme used in CDSX causes the collateral contributions (ACV and SOC) to be much larger than the gross exposures.

Table 2 here

The second interesting finding is the large difference between gross and net exposures in every

\footnotetext{
${ }^{20}$ The importance of CDCS has increased over the past years due to the introduction of new CCP business lines and the recent regulatory efforts to clear all standardized derivatives in a CCP.
} 
system. Gross exposures for CDCS and CDSX show approximately a symmetric distribution around their median values. Gross exposures in the LVTS tend to be positive and small, since LVTS participants have incentives to decrease their positions at the end of the day ${ }^{21}$ Risk controls used in these FMIs are effective, and net exposures are rarely negative. In CDCS, sharp and unpredicted changes in the prices of derivatives cleared may have created some stress such that we observe negative net exposures in some cases.

The third interesting finding is the relative differences in exposures across participants. A participant that has the largest median value in one FMI is not necessarily the one with the largest median value in the other two FMIs. For instance, FI7 has the largest median value of gross exposures in CDSX, but it has the lowest median value in CDCS. These findings show that there is a relatively large heterogeneity in exposures across participants and FMIs.

Figure 5 shows the evolution of exposures across systems and years. They provide interesting information about the period when there was a larger variation in exposures. A first interesting result is that CDCS had the largest volatility at the height of the recent financial crisis, in the autumn of 2008. Perhaps a bit surprisingly, CDSX exhibited relatively homogeneous behavior in recent years, even during the crisis period.

In the LVTS, we observe a substantial variation in exposures across the years. End-of-day exposures during the years 2009-10 were substantially different from other years. Interestingly, net exposures show a significant increase in the winter of 2010, which was not observed for the case of gross exposures. A potential explanation for this result is the changes in collateral policies adopted during the recent crisis to alleviate the financial stress of LVTS participants ${ }^{22}$

\subsection{Systemic risk measures}

Table 3 shows the estimated joint and conditional probabilities (expressed in percentages) for the same seven large participants (P1-P7) shown in Table 2, We use the extreme value theory

\footnotetext{
${ }^{21}$ At the end of the day, any short or long positions in the LVTS must be settled, either through interbank trades or with the central bank at a penalty rate (Allen et al. 2015 ).

${ }^{22}$ For instance, starting in late 2008, non-mortgage loan portfolios were temporarily eligible for collateral in the LVTS. The temporary measure was adopted to provide LVTS participants with greater flexibility in managing their collateral. As conditions in funding markets improved, the proportion of non-mortgage loan portfolios to total collateral pledged allowed was gradually reduced from 100 per cent to 20 per cent, effective April 2010.
} 
methodology to calculate these probabilities. The detailed explanation of the extreme value method is reported in Appendix A.

The results in these tables are calculated by considering the thresholds $Q_{5}$ equal to $5 \%$-quantiles of the corresponding exposures (i.e., $\operatorname{Pr}\left(E_{j}^{b} \leq Q_{5}\right)=5 \%$ for any $b$ and $j$ ) obtained for each FMI and participant.

\section{Table 3 here}

Panel A in Table 3 reports the joint probabilities corresponding to gross exposures for two and three FMIs. These joint probabilities are small, indicating that the systemic risk is low. In general, $P\left[E_{C D S X} \leq Q_{5}, E_{L V T S} \leq Q_{5}\right]$ is the largest across participants, suggesting that CDSX and the LVTS have a stronger dependence on gross exposures than the other two systems. On average, the interdependence between CDSX and the LVTS is 75\% higher than for CDCS and CDSX, and 55\% larger than for CDCS and the LVTS. On the other hand, P1 is, on average, the largest contributor to systemic risk $(0.183 \%)$, followed by P3 (0.18\%) and P6 (0.16\%).

Panel B reports the contributions to systemic risk of one FMI to two FMIs by a participant. On average, $P\left[E_{C D C S} \leq Q_{5}, E_{C D S X} \leq Q_{5} \mid E_{L V T S} \leq Q_{5}\right]$ is larger $(0.216 \%)$ than $P\left[E_{C D C S} \leq\right.$ $\left.Q_{5}, E_{C D S X} \leq Q_{5}\right]$ from Panel A $(0.16 \%)$, suggesting that the LVTS has a relatively large contribution to systemic risk in the other two FMIs. We also find that CDSX contributes to systemic risk in CDCS and the LVTS. On the other hand, we find that $P\left[E_{C D S X} \leq Q_{5}, E_{L V T S} \leq Q_{5} \mid E_{C D C S} \leq\right.$ $\left.Q_{5}\right]<P\left[E_{C D S X} \leq Q_{5}, E_{L V T S} \leq Q_{5}\right]$, suggesting that CDCS does not significantly contribute to systemic risk in the other two systems.

By comparing the remainder of the conditional probabilities in Panel B, we can find interesting results. On average, the contributions of two FMIs to to the systemic risk of a third one are larger than the contributions of one FMI to another one. This result suggests that it is more likely that one FMI is in stress if the other two are also in stress. We also observe that CDCS and CDSX jointly provide the largest systemic risk contribution to LVTS, with $6.65 \%$.

Panels $\mathrm{C}$ and D provide information for the case of net exposures. Overall, contributions to systemic risk in terms of joint or conditional probabilities are larger for net exposures than for gross exposures. Since net exposures are equal to gross exposures plus collateral, this suggests 
that there could be some positive correlation between collateral levels across FMIs. Also, when comparing participants, $\mathrm{P} 7$ is the largest contributor to systemic risk in terms of joint net exposures, with $0.516 \%$, followed by P6 with $0.386 \%$.

In summary, we find that, on average, P1, P3, P6 and P7 have larger systemic risk contributions than the remainder of the participants.

\subsection{Systemic risk across FMIs and participants in financial distress}

In Table 4 we show key statistics for the value of the difference $\Delta_{b}$ in Eq. (8) where we use $5 \%$ quantiles in all cases. We consider all participants with publicly traded stock (see Table 1 for some statistics of stock returns used in our sample). The statistics of $\Delta_{b}$ are calculated across all participants for unconditional and conditional probabilities, gross and net exposures. We observe large statistical dispersion in all cases, but when considering average values, the majority of the cases considered give a value $\Delta_{b}>0$. Cases where $\Delta_{b}>0$ are about twice as frequent as cases where $\Delta_{b}<0$. This suggests that, on average, participants in financial distress are more likely to contribute to systemic risk in the network of FMIs.

In addition, dispersion of the values of $\Delta_{b}$ suggest that there is significant heterogeneity across participants. Therefore, there are participants that can be considered as more systemically important than others because they contribute more to systemic risk in the network of FMIs in case of financial stress.

\section{Table 4 here}

\section{Conclusion}

We propose a measure of systemic risk in the network of FMIs by considering participant-based interdependencies that arise from the activities of one participant in two or more FMIs. Our paper provides a new framework and a methodology to measure systemic risk in the network of FMIs that has not been previously considered in the literature.

We find a rich set of results. Some participants have a larger contribution to systemic risk than 
other participants. When conditioning on the financial distress of participants, we find that, on average, participants that are more likely to be in financial distress are also more likely to contribute to systemic risk in the network of FMIs. All these results suggest that our work could be useful in better understanding the systemic risk contributions of participants in the network of FMIs, which could have relevant implications for the appropriate macroprudential regulation of the financial system.

Although our approach has limitations, we see it as the first stage of a long-term research agenda that could help us to better understand the most effective ways of implementing the regulation and oversight of systemically important FMIs, which may require a more detailed system-wide analysis. This could have important implications for more effective macroprudential regulation of the financial system. 


\section{References}

Acharya, V. V., Pedersen, L. H., Philippon, T. and Richardson, M. P. (2010). Measuring systemic risk. Working Paper, Federal Reserve Bank of Cleveland.

Adrian, T. and Brunnermeier, M. (2015). CoVaR. forthcoming, American Economic Review.

Allen, J., Chapman, J., Echenique, F. and Shum, M. (2015). Efficiency and bargaining power in the interbank loan market. forthcoming, International Economic Review.

- Hortaçsu, A. and Kastl, J. (2011). Analyzing default risk and liquidity demand during a financial crisis: The case of Canada. Bank of Canada Working Paper.

Anderson, S., Dion, J. and Perez Saiz, H. (2013). To link or not to link? Netting and exposures between central counterparties. Journal of Financial Market Infrastructures, 1 (4), 3-29.

Arjani, N. and Mcvanel, D. (2006). A primer on Canada's Large Value Transfer System. Working Paper, Bank of Canada.

Bech, M. L., Chapman, J. T. and Garratt, R. J. (2010). Which bank is the "central" bank? Journal of Monetary Economics, 57 (3), 352-363.

BIS (2008). The interdependencies of payment and settlement systems. Report, Bank for International Settlements, Committee on Payment and Settlement Systems.

BIS (2012). Principles for financial market infrastructures. Report, Bank for International Settlements, Committee on Payment and Settlement Systems.

Chapman, J., Embree, L., Roberts, T. and Zhang, N. (2011). Payment networks: A review of recent research. Bank of Canada Review, 2010 (Winter), 21-27.

Cruz lopez, J. A., Harris, J. H., Hurlin, C. and Pérignon, C. (2013). CoMargin. Bank of Canada Working Paper.

Danielsson, J. and De VRies, C. G. (2000). Value-at-risk and extreme returns. Annales d'Economie et de Statistique, pp. 239-270. 
De Haan, L., Jansen, D. W., Koedijk, K. and de Vries, C. G. (1994). Safety first portfolio selection, extreme value theory and long run asset risks. In Extreme value theory and applications, Springer, pp. 471-487.

Duffie, D., Scheicher, M. and Vuillemey, G. (2015). Central clearing and collateral demand. Journal of Financial Economics.

Embree, L. and Millar, K. (2008). The effects of a disruption in CDSX settlement on activity in the LVTS: A simulation study. Bank of Canada Discussion Paper.

— and Roberts, T. (2009). Network analysis and canada's Large Value Transfer System. Bank of Canada Discussion Paper.

Fisher, R. A. and Tippett, L. H. C. (1928). Limiting forms of the frequency distribution of the largest or smallest member of a sample. In Mathematical Proceedings of the Cambridge Philosophical Society, Cambridge Univ Press, vol. 24, pp. 180-190.

Goldie, C. M. and Smith, R. L. (1987). Slow variation with remainder: Theory and applications. The Quarterly Journal of Mathematics, 38 (1), 45-71.

Gravelle, T. and Li, F. (2013). Measuring systemic importance of financial institutions: An extreme value theory approach. Journal of Banking \& Finance, 37 (7), 2196-2209.

Hartmann, P., Straetmans, S. and De Vries, C. G. (2005). Banking system stability: A cross-atlantic perspective. National Bureau of Economic Research, Working Paper Series.

HiLL, B. M. et al. (1975). A simple general approach to inference about the tail of a distribution. The annals of statistics, 3 (5), 1163-1174.

International Swaps And Derivatives Association (2013). CCP loss allocation at the end of the waterfall. ISDA Discussion Paper.

Jansen, D. W. and De Vries, C. G. (1991). On the frequency of large stock returns: Putting booms and busts into perspective. The Review of Economics and Statistics, pp. 18-24.

Jones, R. A. and PÉRIGnon, C. (2013). Derivatives clearing, default risk, and insurance. Journal of Risk and Insurance, 80 (2), 373-400. 
Kahn, C. M. and Roberds, W. (2000). The CLS bank: a solution to the risks of international payments settlement? Working Paper, Federal Reserve Bank of Atlanta.

LEDFORD, A. W. and TAWn, J. A. (1996). Statistics for near independence in multivariate extreme values. Biometrika, 83 (1), 169-187.

LeHAR, A. (2005). Measuring systemic risk: A risk management approach. Journal of Banking $\&$ Finance, 29 (10), 2577-2603.

León, C., Berndsen, R. and Renneboog, L. (2014). Financial stability and interacting networks of financial institutions and market infrastructures. Center Discussion Paper, Tilburg University.

— and PÉREZ, J. (2014). Assessing financial market infrastructures' systemic importance with authority and hub centrality. Journal of Financial Market Infrastructures, 2 (3), 67-87.

MÄGerle, J. and Nellen, T. (2015). Interoperability between central counterparties. Journal of Financial Market Infrastructures, 4 (2), 49-71.

McVanel, D. (2003). CDSX: Canada's new clearing and settlement system for securities. Bank of Canada Financial System Review, pp. 59-64.

Menkveld, A. J., Pagnotta, E. and Zoican, M. A. (2015). Does central clearing affect price stability? Evidence from Nordic equity markets. Tinbergen Institute Discussion Paper 13-181.

Merton, R. C. (1974). On the pricing of corporate debt: The risk structure of interest rates. The Journal of Finance, 29 (2), 449-470.

Miller, P. and Northcott, C. A. (2002). CLS Bank: Managing foreign exchange settlement risk. Bank of Canada Review, 2002 (Autumn), 13-25.

Monnet, C. et al. (2010). Let's Make It Clear: How Central Counterparties saved the day. Federal Reserve Bank of Philadelphia Business Review, 1, 1-10.

OFR (2015). 2015 annual report to congress. Report, Office of Financial Research.

Poon, S.-H., Rockinger, M. and Tawn, J. (2004). Extreme value dependence in financial markets: Diagnostics, models, and financial implications. Review of Financial Studies, 17 (2), $581-610$. 
Quintos, C., Fan, Z. and Phillips, P. C. (2001). Structural change tests in tail behaviour and the asian crisis. The Review of Economic Studies, 68 (3), 633-663.

REID, C. (2005). Credit default swaps and the canadian context. Bank of Canada Financial System Review, pp. 45-51.

Renault, F., Beyeler, W. E., Glass, R. J., Soramäki, K. and Bech, M. L. (2007). Congestion and cascades in coupled payment systems. In Payments and Monetary and Financial Stability, ECB-Bank of England Conference, pp. 12-13.

Segoviano, M. A., Basurto, M. A. S. and Goodhart, C. (2009). Banking stability measures. 627. 


\section{Appendices}

\section{Appendix A Extreme value approach}

For analytical convenience, Eqs. (3), (4) and (5) can in practice be estimated using left quantiles using trivial transformations. For a given significance level $p_{j}$, corresponding to the three systems, there exist three left tail quantiles $Q_{j}\left(p_{j}\right), j=1,2$, and 3 , such that

$$
P\left[E_{1}^{b}>Q_{1}\left(p_{1}\right)\right]=p_{1}, P\left[E_{2}^{b}>Q_{2}\left(p_{2}\right)\right]=p_{2}, \quad P\left[E_{3}^{b}>Q_{3}\left(p_{3}\right)\right]=p_{3}
$$

Note that we can choose $p_{j}$ such that $Q_{j}\left(p_{j}\right)=K_{j}^{b}$ so we can estimate Eq. (3). From elementary probability theory we can now easily write a probability measure by using the notation introduced above,

$$
\begin{aligned}
\tau & =P\left[E_{1}^{b}>Q_{1}\left(p_{1}\right), E_{2}^{b}>Q_{2}\left(p_{2}\right) \mid E_{3}^{b}>Q_{3}\left(p_{3}\right)\right] \\
& =\frac{P\left[E_{1}^{b}>Q_{1}\left(p_{1}\right), E_{2}^{b}>Q_{2}\left(p_{2}\right), E_{3}^{b}>Q_{3}\left(p_{3}\right)\right]}{P\left[E_{3}^{b}>Q_{3}\left(p_{3}\right)\right]} \\
& =\frac{P\left[E_{1}^{b}>Q_{1}\left(p_{1}\right), E_{2}^{b}>Q_{2}\left(p_{2}\right), E_{3}^{b}>Q_{3}\left(p_{3}\right)\right]}{p_{3}} .
\end{aligned}
$$

Given this specification, a proper estimation of $\tau$ is of key importance. If we know a parametric specification of the joint distribution function, $\tau$ can be easily calculated, because we can estimate the distributional parameters using parametric methods. However, since there is no evidence that these exposures follow the same distribution, a serious problem with the parametric specification is the misspecification of the model, which could lead to misleading results in inference and hypothesis testing. To avoid specific parametric assumptions of the distribution, we use the semiparametric extreme value theory approach proposed by Ledford and Tawn (1996) and Poon et al. (2004) to estimate $\tau$. This theory is used to study the limiting distribution of the extreme values of a random variable instead of the distribution of this random variable. According to this theory, even though fat-tailed random variables may follow different distributions, such as a stable Paretian or mixtures of normals, at the limit they all converge to the same underlying distribution. 
The estimation of $\tau$ can be determined by the dependence among exposures and their marginal distributions. We transform the original series $E_{j}^{b}$ to a series with a common marginal distribution. By using that transformation, differences in joint tail probabilities can be purely due to differences in the tail dependence of the extreme exposures.

To be precise, we transform these participants' exposures to unit Pareto marginals,

$$
\widetilde{E}_{j}^{b}=\frac{1}{1-F_{E_{j}^{b}}\left(E_{j}^{b}\right)},
$$

where $F_{E_{j}^{b}}(\cdot)$ represents the marginal cumulative distribution function (cdf) for $E_{j}^{b}$. If we replace the unknown marginal distributions with their empirical distribution functions, we obtain,

$$
\widetilde{E}_{j}^{b}=\frac{n+1}{n+1-R_{E_{j}^{b}}}
$$

where $n$ is the number of observations of $E_{j}^{b}$ and $R_{E_{j}^{b}}$ is the rank order statistic of $E_{j}^{b}$.

By transforming these variables, we can rewrite the joint tail probability $\tau$ as follows,

$$
\begin{aligned}
& P\left[E_{1}^{b}>Q_{1}\left(p_{1}\right), E_{2}^{b}>Q_{2}\left(p_{2}\right), E_{3}^{b}>Q_{3}\left(p_{3}\right)\right] \\
& =P\left[\widetilde{E}_{1}^{b}>q_{1}, \widetilde{E}_{2}^{b}>q_{2}, \widetilde{E}_{3}^{b}>q_{3}\right] \\
& =P\left[\widetilde{E}_{1}^{b}>q_{1}, \widetilde{E}_{2}^{b} \cdot \frac{q_{1}}{q_{2}}>q_{1}, \widetilde{E}_{3}^{b} \cdot \frac{q_{1}}{q_{3}}>q_{1}\right] \\
& =P\left[\widehat{E}_{1}^{b}>q_{1}, \widehat{E}_{2}^{b}>q_{1}, \widehat{E}_{3}^{b}>q_{1}\right],
\end{aligned}
$$

where we have used the additional transformation $\widehat{E}_{j}^{b}=\widetilde{E}_{j}^{b} \frac{q_{1}}{q_{j}}$. Additionally, we can transform Eq. (22) as follows:

$$
\begin{aligned}
P\left[\widehat{E}_{1}^{b}\right. & \left.>q_{1}, \widehat{E}_{2}^{b}>q_{1}, \widehat{E}_{3}^{b}>q_{1}\right] \\
& =P\left[\min \left(\widehat{E}_{1}^{b}, \widehat{E}_{2}^{b}\right)>q, \widehat{E}_{3}^{b}>q\right] \\
& =P\left[\min \left\{\min \left(\widehat{E}_{1}^{b}, \widehat{E}_{2}^{b}\right), \widehat{E}_{3}^{b}\right\}>q\right] \\
& =P\left[Z_{1}>q_{1}, Z_{2}>q_{1}\right]=P[Z>q]
\end{aligned}
$$


where $q \equiv q_{1}=1 / p_{1}, Z_{1}=\min \left(\widehat{E}^{b}{ }_{1}, \widehat{E}_{2}^{b}\right), Z_{2}=\widehat{E}_{3}^{b}$. And $Z=\min \left\{Z_{1}, Z_{2}\right\}$. Hence, the transformation to unit Pareto marginals reduces the estimation of the multivariate probability to a simple univariate probability. The only assumption that has to be made is that the distribution of the minimum series $Z=\min \left(Z_{1}, Z_{2}\right)$ displays fat tails. Popular distribution models like the Student-t exhibit such behavior.

The univariate tail probability for a fat-tailed random variable can be estimated by using the semiparametric probability estimator from De Haan et al. (1994),

$$
\hat{P}[Z>q]=\frac{k}{n}\left(\frac{C_{n-k, n}}{q}\right)^{\alpha}
$$

where $\alpha>0$ is an unknown parameter and the tail cut-off point $C_{n-k, n}$ is the $(n-k)$-th ascending order statistic from the cross-sectional minimum series such that $\lim _{n \rightarrow \infty}[1 / k(n)]=0$ and $k=o(n)$.

This tail probability estimator in Eq. (25) depends on the tail index $\alpha$ and the threshold parameter $k 2^{23}$ This tail index $\alpha$ captures the tail probability's rate of decay in the probability. Clearly, the lower $\alpha$ is, the slower the probability decay and the higher the probability mass in the tail of $Z$.

To estimate $\alpha$, we use the popular Hill et al. (1975) estimator for the index of regular variation $\eta$

$$
\hat{\eta}=\frac{1}{m} \sum_{j=0}^{m-1} \ln \left(\frac{C_{n-j, n}}{C_{n-m, n}}\right)=\frac{1}{\hat{\alpha}},
$$

where $\hat{\eta}$ is the estimate of the parameter of tail dependence. A relatively high $\hat{\eta}$ corresponds with a relatively high dependence of the components $\left(\widetilde{E}_{1}, \ldots, \widetilde{E}_{m}\right) k$. Further details on the Hill estimator can be found in Jansen and De Vries (1991) ${ }^{24}$

The choice of the threshold parameter $k$ is a point of concern in the extreme value theory literature. If $k$ is set too low, too few observations are considered in the estimation. If one considers

\footnotetext{
${ }^{23}$ This estimator basically extends the empirical distribution of $Z$ outside the domain of the sample by means of its asymptotic Pareto tail from $P[Z>q] \approx l(q) q^{-\alpha}, \alpha \geq 1$ with $q$ large and where $l(q)$ is a slowly varying function (i.e., $\lim _{q \rightarrow \infty} l(x q) / l(q)=1$ for all fixed $x>0$ ). An intuitive derivation of the estimator is provided in Danielsson and De Vries (2000).

${ }^{24}$ Quintos et al. (2001) develop a number of tests for identifying single unknown breaks in the estimator of the tail index $\alpha(\eta)$. Their tests are used to assess whether breakpoints in asset return distributions exist for Asian stock markets. In addition, Hartmann et al. (2005) use these tests to assess various hypotheses regarding the evolution and structure of systemic risk in the banking system.
} 
a large $k$, non-tail events may enter the estimation. Hence, if one includes too many observations, the variance of the estimate is reduced at the expense of a bias in the tail estimation. With too few observations, the bias declines but the variance of the estimate becomes too large. A number of methods have been proposed to select $k$ in finite samples. Goldie and Smith (1987) suggest selecting the parameter $k$ so as to minimize the asymptotic mean-squared error. In our paper, we use the widely used heuristic procedure by plotting the tail estimator as a function of $k$ and select $k$ in a region where $\hat{\eta}$ is stable. 


\section{Appendix B Empirical results}

\section{Table 1: Statistics of log daily stock returns}

This table shows key statistics of the distribution of log daily stock returns for the years $2004-11$ for all FMI participants with publicly traded stock (common equity). Log daily stock returns are defined as the first difference of $\log$ daily stock prices. $\mathrm{pX}$ is the $\mathrm{X} \%$-quantile of the sample. A log daily stock return is defined as the first difference of the price changes in stock, $\log \left(P^{b}(t)\right)-\log \left(P^{b}(t-1)\right)$.

\begin{tabular}{|c|c|c|c|c|c|c|c|c|c|c|}
\hline & Mean & Min & $\mathrm{p} 1$ & p5 & $\mathrm{p} 25$ & $\mathrm{p} 50$ & p75 & p95 & p99 & Max \\
\hline All years & 0.0002 & -0.8925 & -0.0590 & -0.0298 & -0.0080 & 0.0003 & 0.0085 & 0.0292 & 0.0595 & 0.3239 \\
\hline 2004 & 0.0003 & -0.0966 & -0.0278 & -0.0170 & -0.0059 & 0.0004 & 0.0066 & 0.0176 & 0.0276 & 0.0566 \\
\hline 2005 & 0.0006 & -0.0785 & -0.0227 & -0.0142 & -0.0048 & 0.0004 & 0.0057 & 0.0163 & 0.0263 & 0.0871 \\
\hline 2006 & 0.0007 & -0.0860 & -0.0263 & -0.0173 & -0.0054 & 0.0008 & 0.0067 & 0.0184 & 0.0314 & 0.0699 \\
\hline 2007 & -0.0004 & -0.0822 & -0.0435 & -0.0266 & -0.0078 & -0.0001 & 0.0072 & 0.0240 & 0.0431 & 0.0852 \\
\hline 2008 & -0.0024 & -0.3185 & -0.1322 & -0.0615 & -0.0204 & -0.0024 & 0.0154 & 0.0617 & 0.1228 & 0.3239 \\
\hline 2009 & 0.0017 & -0.8925 & -0.0898 & -0.0480 & -0.0141 & 0.0015 & 0.0172 & 0.0534 & 0.1146 & 0.2727 \\
\hline 2010 & 0.0001 & -0.1369 & -0.0471 & -0.0262 & -0.0083 & 0.0004 & 0.0086 & 0.0260 & 0.0415 & 0.1898 \\
\hline 2011 & -0.0007 & -0.1399 & -0.0632 & -0.0330 & -0.0094 & -0.0006 & 0.0085 & 0.0294 & 0.0603 & 0.1564 \\
\hline
\end{tabular}




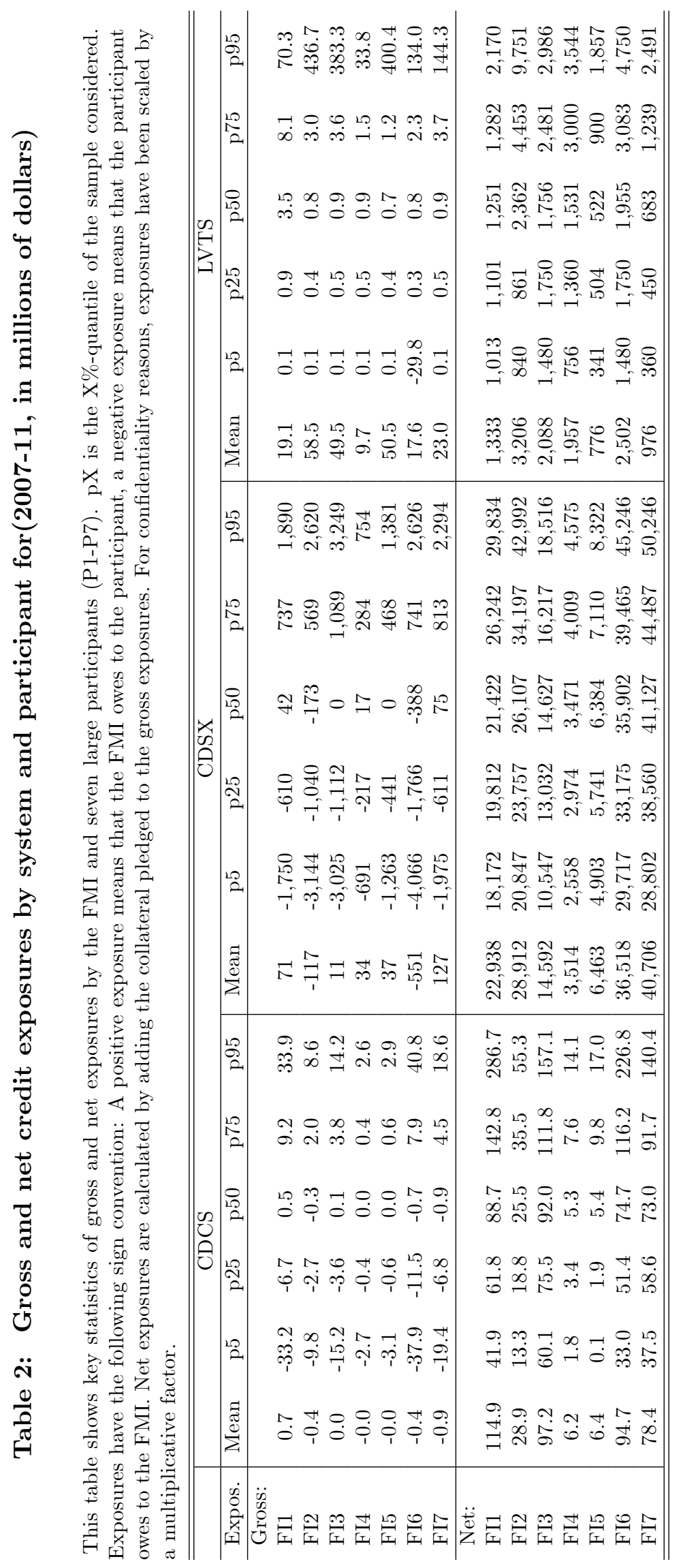




\section{Table 3: Joint and conditional probabilities (in percentages) for a selected group of participants}

This table shows joint and conditional probabilities (expressed in percentages) that gross and net exposures are below thresholds $Q_{5}$ for every FMI and participant P1-P7. We use 5\%-quantiles to calculate these thresholds.We only report $P\left[E_{C D C S} \leq Q_{5}, E_{C D S X} \leq Q_{5} \mid E_{L V T S} \leq Q_{5}\right]$ because by Bayes-Rule and the use of identical quantiles for all FMIs, this probability is identical to the case where we condition on a different FMI.

\begin{tabular}{|c|c|c|c|c|c|c|c|c|}
\hline Type of exposure & P1 & P2 & P3 & P4 & P5 & P6 & P7 & Average \\
\hline \multicolumn{9}{|l|}{ Panel A: Joint Gross Exposures: } \\
\hline$P\left[E_{C D C S} \leq Q_{5}, E_{C D S X} \leq Q_{5}, E_{L V T S} \leq Q_{5}\right]$ & $6.0 \mathrm{e}-03$ & $7.6 \mathrm{e}-03$ & $2.9 \mathrm{e}-02$ & $9.0 \mathrm{e}-03$ & $2.9 \mathrm{e}-03$ & $2.0 \mathrm{e}-02$ & $1.2 \mathrm{e}-03$ & $1.1 \mathrm{e}-02$ \\
\hline$P\left[E_{C D C S} \leq Q_{5}, E_{C D S X} \leq Q_{5}\right]$ & $1.5 \mathrm{e}-01$ & $2.5 \mathrm{e}-01$ & $2.4 \mathrm{e}-01$ & $2.1 \mathrm{e}-01$ & $6.2 \mathrm{e}-02$ & $1.1 \mathrm{e}-01$ & $8.6 \mathrm{e}-02$ & $1.6 \mathrm{e}-01$ \\
\hline$P\left[E_{C D C S} \leq Q_{5}, E_{L V T S} \leq Q_{5}\right]$ & $2.8 \mathrm{e}-01$ & $1.0 \mathrm{e}-01$ & $2.2 \mathrm{e}-01$ & $1.0 \mathrm{e}-01$ & $3.1 \mathrm{e}-01$ & $8.9 \mathrm{e}-02$ & $1.8 \mathrm{e}-01$ & $1.8 \mathrm{e}-01$ \\
\hline$P\left[E_{C D S X} \leq Q_{5}, E_{L V T S} \leq Q_{5}\right]$ & $3.0 \mathrm{e}-01$ & $2.5 \mathrm{e}-01$ & $2.3 \mathrm{e}-01$ & $2.2 \mathrm{e}-01$ & $1.9 \mathrm{e}-01$ & $4.2 \mathrm{e}-01$ & $3.7 \mathrm{e}-01$ & $2.8 \mathrm{e}-01$ \\
\hline Average & 0.183 & 0.150 & 0.180 & 0.137 & 0.141 & 0.160 & 0.158 & 0.158 \\
\hline \multicolumn{9}{|l|}{ Panel B: Conditional Gross Exposures: } \\
\hline$P\left[E_{C D C S} \leq Q_{5}, E_{C D S X} \leq Q_{5} \mid E_{L V T S} \leq Q_{5}\right]$ & 0.120 & 0.153 & 0.585 & 0.180 & 0.058 & 0.391 & 0.025 & 0.216 \\
\hline$P\left[E_{C D C S} \leq Q_{5} \mid E_{C D S X} \leq Q_{5}, E_{L V T S} \leq Q_{5}\right]$ & 2.538 & 3.161 & 16.485 & 4.067 & 2.093 & 4.509 & 1.234 & 4.870 \\
\hline$P\left[E_{C D S X} \leq Q_{5} \mid E_{C D C S} \leq Q_{5}, E_{L V T S} \leq Q_{5}\right]$ & 2.816 & 8.909 & 9.158 & 10.653 & 0.999 & 6.792 & 1.418 & 5.821 \\
\hline$P\left[E_{L V T S} \leq Q_{5} \mid E_{C D C S} \leq Q_{5}, E_{C D S X} \leq Q_{5}\right]$ & 4.133 & 3.089 & 12.012 & 4.191 & 4.622 & 17.089 & 1.439 & 6.654 \\
\hline$P\left[E_{C D C S} \leq Q_{5} \mid E_{C D S X} \leq Q_{5}\right]$ & 2.920 & 4.939 & 4.835 & 4.292 & 1.248 & 2.299 & 1.717 & 3.179 \\
\hline$P\left[E_{C D C S} \leq Q_{5} \mid, E_{L V T S} \leq Q_{5}\right]$ & 5.522 & 2.006 & 4.433 & 2.017 & 6.173 & 1.771 & 3.526 & 3.635 \\
\hline$P\left[E_{C D S X} \leq Q_{5} \mid E_{L V T S} \leq Q_{5}\right]$ & 6.096 & 4.939 & 4.557 & 4.462 & 3.788 & 8.358 & 7.350 & 5.650 \\
\hline Average & 3.449 & 3.885 & 7.438 & 4.266 & 2.712 & 5.887 & 2.387 & 4.289 \\
\hline \multicolumn{9}{|l|}{ Panel C: Joint Net Exposures: } \\
\hline$P\left[E_{C D C S} \leq Q_{5}, E_{C D S X} \leq Q_{5}, E_{L V T S} \leq Q_{5}\right]$ & $5.1 \mathrm{e}-02$ & $2.0 \mathrm{e}-04$ & $1.7 \mathrm{e}-04$ & $1.8 \mathrm{e}-03$ & $2.9 \mathrm{e}-05$ & $2.3 \mathrm{e}-02$ & $7.5 \mathrm{e}-02$ & $2.2 \mathrm{e}-02$ \\
\hline$P\left[E_{C D C S} \leq Q_{5}, E_{C D S X} \leq Q_{5}\right]$ & $2.1 \mathrm{e}-01$ & $3.7 \mathrm{e}-02$ & $2.6 \mathrm{e}-01$ & $1.4 \mathrm{e}-01$ & $1.1 \mathrm{e}-01$ & $2.7 \mathrm{e}-01$ & $4.1 \mathrm{e}-01$ & $2.0 \mathrm{e}-01$ \\
\hline$P\left[E_{C D C S} \leq Q_{5}, E_{L V T S} \leq Q_{5}\right]$ & $1.2 \mathrm{e}+00$ & $1.4 \mathrm{e}-01$ & $1.5 \mathrm{e}-02$ & $4.4 \mathrm{e}-03$ & $8.2 \mathrm{e}-01$ & $5.7 \mathrm{e}-01$ & $1.1 \mathrm{e}-01$ & $4.0 \mathrm{e}-01$ \\
\hline$P\left[E_{C D S X} \leq Q_{5}, E_{L V T S} \leq Q_{5}\right]$ & $8.1 \mathrm{e}-02$ & $4.1 \mathrm{e}-06$ & $7.8 \mathrm{e}-02$ & $3.2 \mathrm{e}-04$ & $2.8 \mathrm{e}-02$ & $6.8 \mathrm{e}-01$ & $1.5 \mathrm{e}+00$ & $3.3 \mathrm{e}-01$ \\
\hline Average & 0.374 & 0.045 & 0.089 & 0.037 & 0.239 & 0.386 & 0.516 & 0.241 \\
\hline \multicolumn{9}{|l|}{ Panel D: Conditional Net Exposures: } \\
\hline$P\left[E_{C D C S} \leq Q_{5}, E_{C D S X} \leq Q_{5} \mid E_{L V T S} \leq Q_{5}\right]$ & 1.023 & 0.004 & 0.003 & 0.036 & 0.001 & 0.469 & 1.498 & 0.434 \\
\hline$P\left[E_{C D C S} \leq Q_{5} \mid E_{C D S X} \leq Q_{5}, E_{L V T S} \leq Q_{5}\right]$ & 15.638 & 1.722 & 0.275 & 2.858 & 0.136 & 8.341 & 21.118 & 7.155 \\
\hline$P\left[E_{C D S X} \leq Q_{5} \mid E_{C D C S} \leq Q_{5}, E_{L V T S} \leq Q_{5}\right]$ & 4.877 & 4.572 & 35.608 & 3.439 & 2.100 & 3.925 & 15.515 & 10.005 \\
\hline$P\left[E_{L V T S} \leq Q_{5} \mid E_{C D C S} \leq Q_{5}, E_{C D S X} \leq Q_{5}\right]$ & 20.691 & 0.569 & 0.065 & 1.302 & 0.027 & 8.874 & 18.347 & 7.125 \\
\hline$P\left[E_{C D C S} \leq Q_{5} \mid E_{C D S X} \leq Q_{5}\right]$ & 4.168 & 0.742 & 5.254 & 2.798 & 2.157 & 5.316 & 8.144 & 3.633 \\
\hline$P\left[E_{C D C S} \leq Q_{5} \mid, E_{L V T S} \leq Q_{5}\right]$ & 23.113 & 2.848 & 0.309 & 0.088 & 16.438 & 11.443 & 2.252 & 4.155 \\
\hline$P\left[E_{C D S X} \leq Q_{5} \mid E_{L V T S} \leq Q_{5}\right]$ & 1.616 & 0.000 & 1.558 & 0.006 & 0.556 & 13.628 & 29.396 & 6.457 \\
\hline Average & 10.161 & 1.494 & 6.153 & 1.504 & 3.059 & 7.428 & 13.753 & 5.566 \\
\hline
\end{tabular}




\section{Table 4: Systemic risk across FMIs and participants in financial distress}

This table shows mean and standard deviation for $\Delta_{b}$ in Eq. (4) across participants, and expressed as a percent. Statistics are calculated across all participants using the entire sample. If $\Delta_{b}<0$, participants in financial distress contribute less to systemic risk in the network of FMIs. On the other hand, if $\Delta_{b}>0$, participants in financial distress contribute more to systemic risk in the network of FMIs. We use 5\%-quantiles to calculate the thresholds for FMI indicators and stock returns.

\begin{tabular}{|c|c|c|}
\hline Probability & mean & $\mathrm{sd}$ \\
\hline \multicolumn{3}{|l|}{ Gross exposures: } \\
\hline \multicolumn{3}{|l|}{ Joint probabilities: } \\
\hline$\Delta_{b}\left(E_{C D C S}, E_{C D S X}, E_{L V T S}\right)$ & 0.03 & 0.07 \\
\hline$\Delta_{b}\left(E_{C D C S}, E_{C D S X}\right)$ & 0.54 & 0.77 \\
\hline$\Delta_{b}\left(E_{C D C S}, E_{L V T S}\right)$ & 0.44 & 0.85 \\
\hline & 0.22 \\
\hline$\Delta_{b}\left(E_{C D C S}, E_{C D S X} \mid E_{L V T S}\right)$ & 0.64 & 1.58 \\
\hline$\Delta_{b}\left(E_{C D C S}, E_{L V T S} \mid E_{C D S X}\right)$ & 0.48 & 0.90 \\
\hline$\Delta_{b}\left(E_{C D C S}, E_{L V T S} \mid E_{C D S X}\right)$ & 0.01 & 0.35 \\
\hline$\Delta_{b}\left(E_{C D C S} \mid E_{C D S X}, E_{L V T S}\right)$ & 4.72 & 9.47 \\
\hline$\Delta_{b}\left(E_{C D S X}, E_{C D C S} \mid E_{L V T S}\right)$ & 0.73 & 7.21 \\
\hline$\Delta_{b}\left(E_{L V T S}, E_{C D C S} \mid E_{C D S X}\right)$ & -2.63 & 7.77 \\
\hline$\Delta_{b}\left(E_{C D C S} \mid E_{C D S X}\right)$ & 9.62 & 12.39 \\
\hline$\Delta_{b}\left(E_{C D C S} \mid E_{L V T S}\right)$ & 7.72 & 10.91 \\
\hline$\Delta_{b}\left(E_{C D S X} \mid E_{L V T S}\right)$ & -1.61 & 2.60 \\
\hline \multicolumn{3}{|l|}{ Net exposures: } \\
\hline \multicolumn{3}{|l|}{ Joint probabilities: } \\
\hline$\Delta_{b}\left(E_{C D C S}, E_{C D S X}, E_{L V T S}\right)$ & -0.01 & 0.02 \\
\hline$\Delta_{b}\left(E_{C D C S}, E_{C D S X}\right)$ & 0.13 & 0.34 \\
\hline$\Delta_{b}\left(E_{C D C S}, E_{L V T S}\right)$ & -0.30 & 0.27 \\
\hline$\Delta_{b}\left(E_{C D S X}, E_{L V T S}\right)$ & 0.11 & 0.20 \\
\hline \multicolumn{3}{|l|}{ Conditional probabilities: } \\
\hline$\Delta_{b}\left(E_{C D C S}, E_{C D S X} \mid E_{L V T S}\right)$ & -0.25 & 0.37 \\
\hline$\Delta_{b}\left(E_{C D C S}, E_{L V T S} \mid E_{C D S X}\right)$ & -0.21 & 0.35 \\
\hline$\Delta_{b}\left(E_{C D C S}, E_{L V T S} \mid E_{C D S X}\right)$ & 2.83 & 6.69 \\
\hline$\Delta_{b}\left(E_{C D C S} \mid E_{C D S X}, E_{L V T S}\right)$ & 7.08 & 10.49 \\
\hline$\Delta_{b}\left(E_{C D S X}, E_{C D C S} \mid E_{L V T S}\right)$ & 4.28 & 6.87 \\
\hline$\Delta_{b}\left(E_{L V T S}, E_{C D C S} \mid E_{C D S X}\right)$ & 4.89 & 19.74 \\
\hline$\Delta_{b}\left(E_{C D C S} \mid E_{C D S X}\right)$ & 6.13 & 11.67 \\
\hline$\Delta_{b}\left(E_{C D C S} \mid E_{L V T S}\right)$ & -0.33 & 4.92 \\
\hline$\Delta_{b}\left(E_{C D S X} \mid E_{L V T S}\right)$ & -0.57 & 4.44 \\
\hline
\end{tabular}




\section{Appendix C Figures}

Figure 1: Exposures across Canadian FMIs

In this figure we show a simple case of two participants that are members of the three FMIs. A default of participant 1 could be a very stressful event for participant 2 if it needs to use its own resources to cover this default in every FMI.

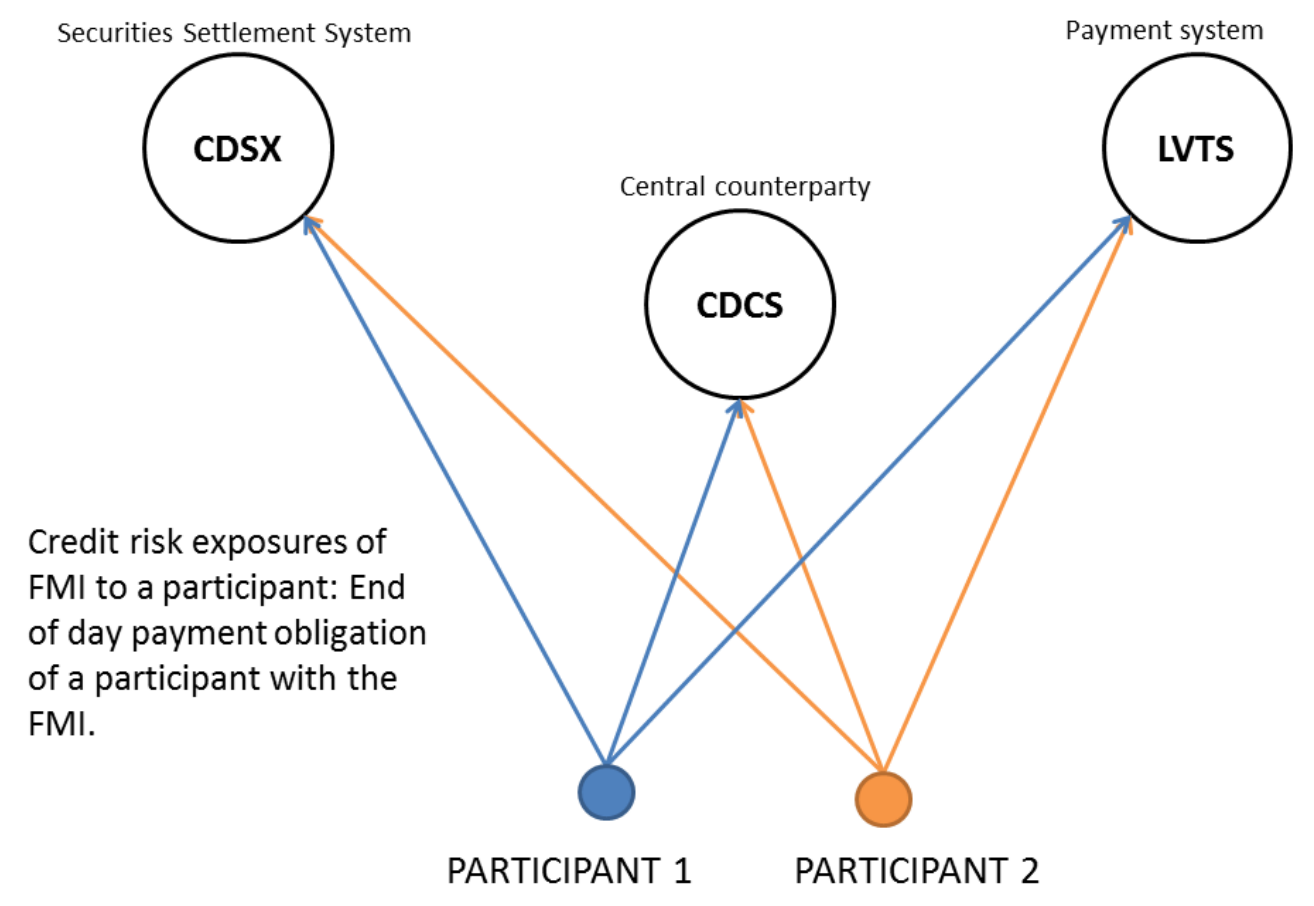


Figure 2: Gross and net credit exposures

In this diagram we represent the distribution of gross and net exposures. We have the following sign convention: A positive exposure means that the FMI owes to the participant; a negative exposure means that the participant owes to the FMI. Net exposures are calculated by adding the collateral pledged to the gross exposures.

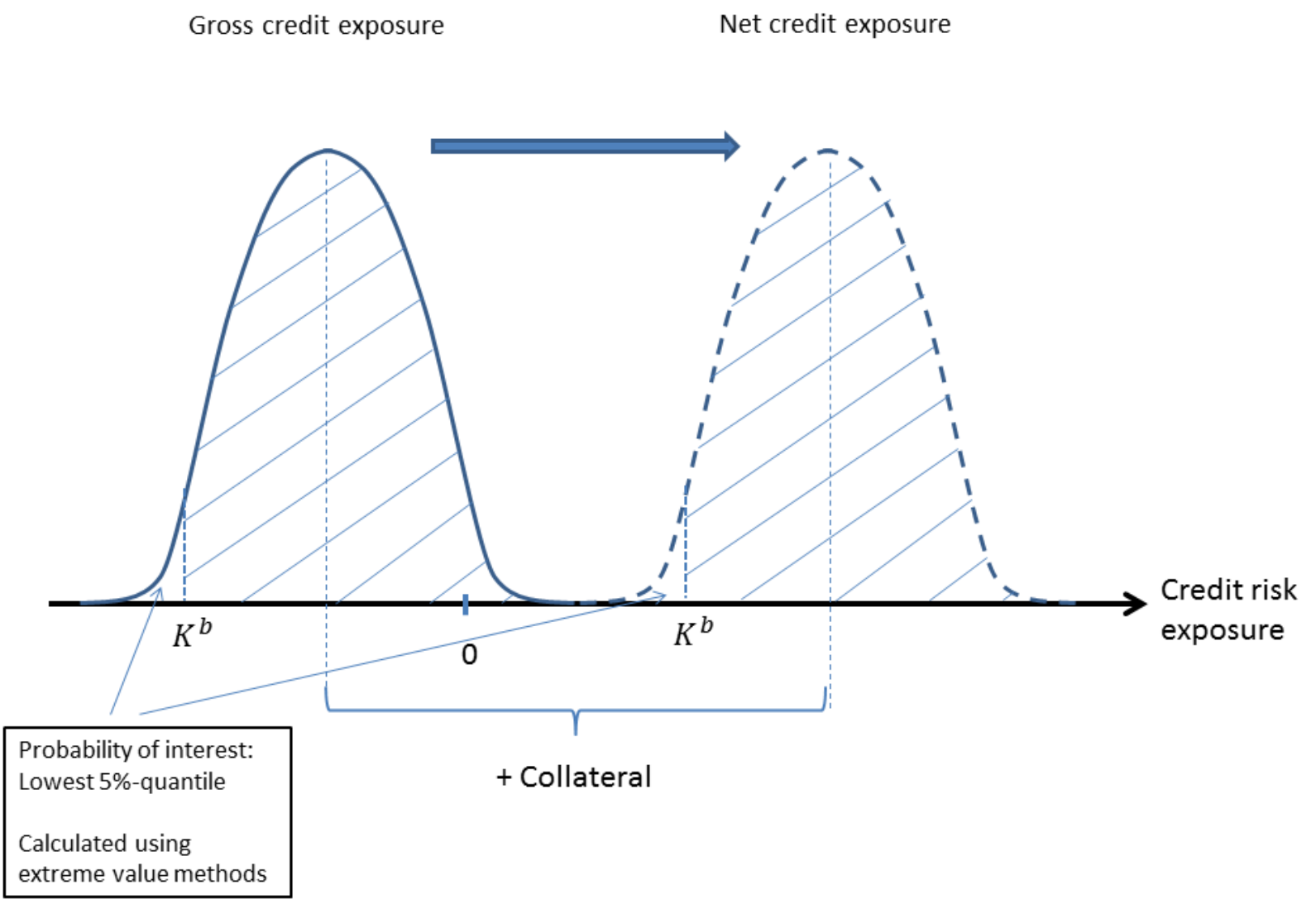


Figure 3: Daily price variation of a 10-year Government of Canada Bond Future ("CNZ08") in November 18th, 2008

We show an example of daily intraday price variations of a future contract traded on the Montréal Exchange and cleared in CDCS.

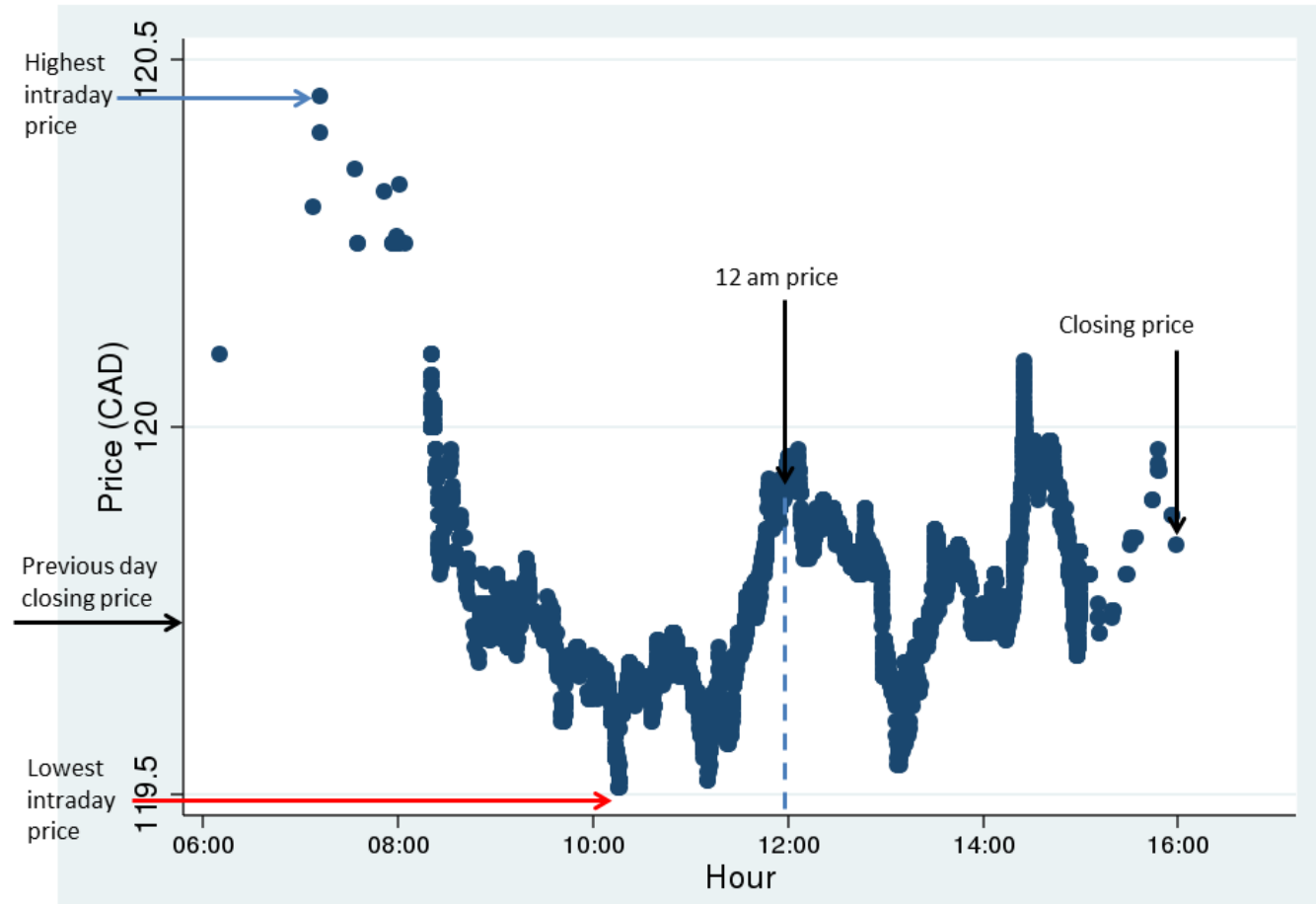


Figure 4: Example of the gross position of an LVTS participant on a representative day

We show the net aggregate position for T1 and T2 for a financial institution in the LVTS for a representative day. A positive (credit) position means that the system owes money to the financial institution (the total amount of payments received is greater than the total amount of payments sent), whereas a negative (debit) position means that the financial institution owes a net amount to the system.

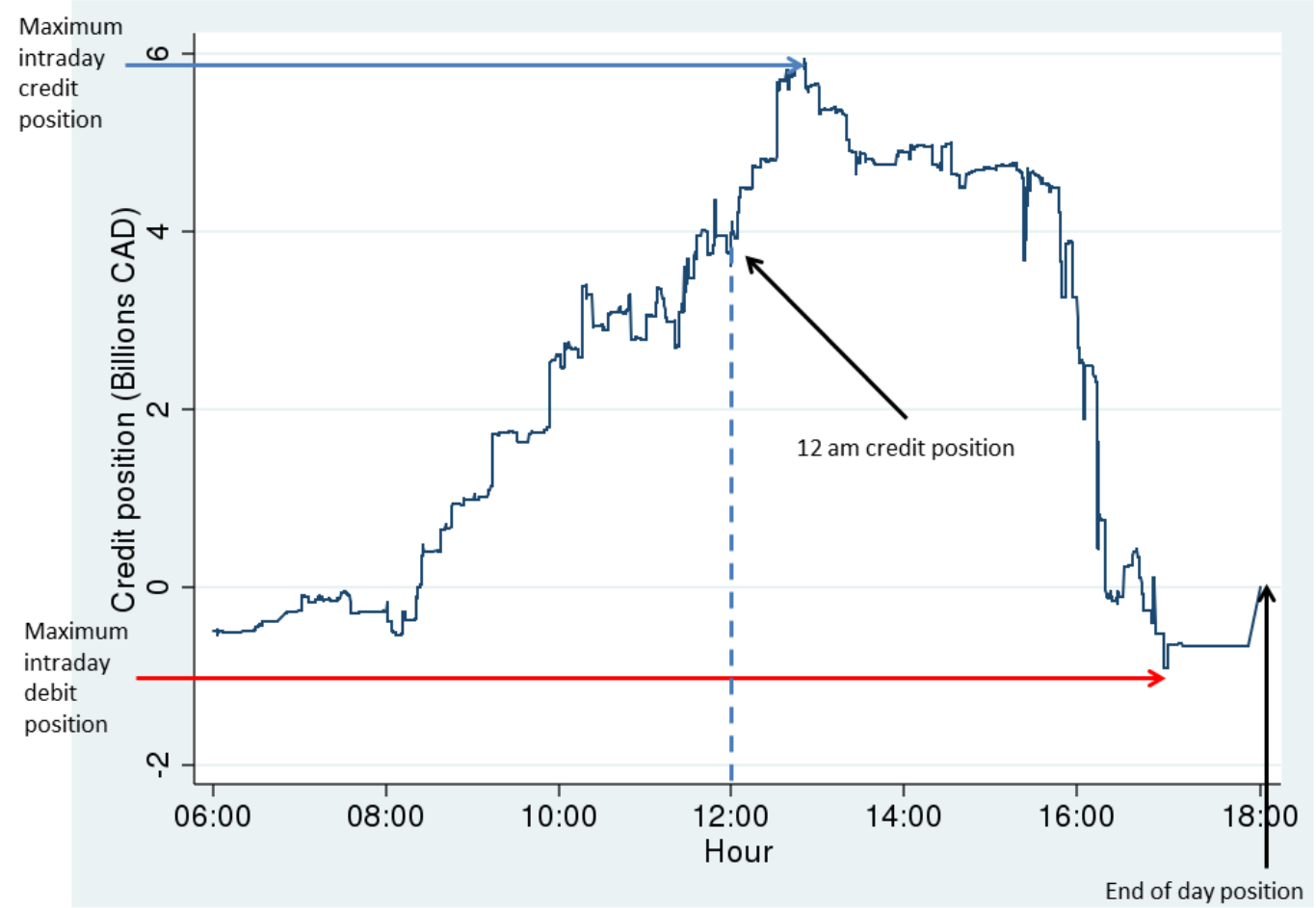




\section{Figure 5: Gross and net exposures of different systems across years (in billions)}

We show end-of-day exposures for the three systems considered, measured in billions of dollars. Gross exposures (before collateral) are in the left column, net exposures (after collateral) in the right column. We have the following sign convention: A positive exposure means that the FMI owes to the participant, a negative exposure means that the participant owes to the FMI. Net exposures are calculated by adding the collateral pledged to the gross exposures.
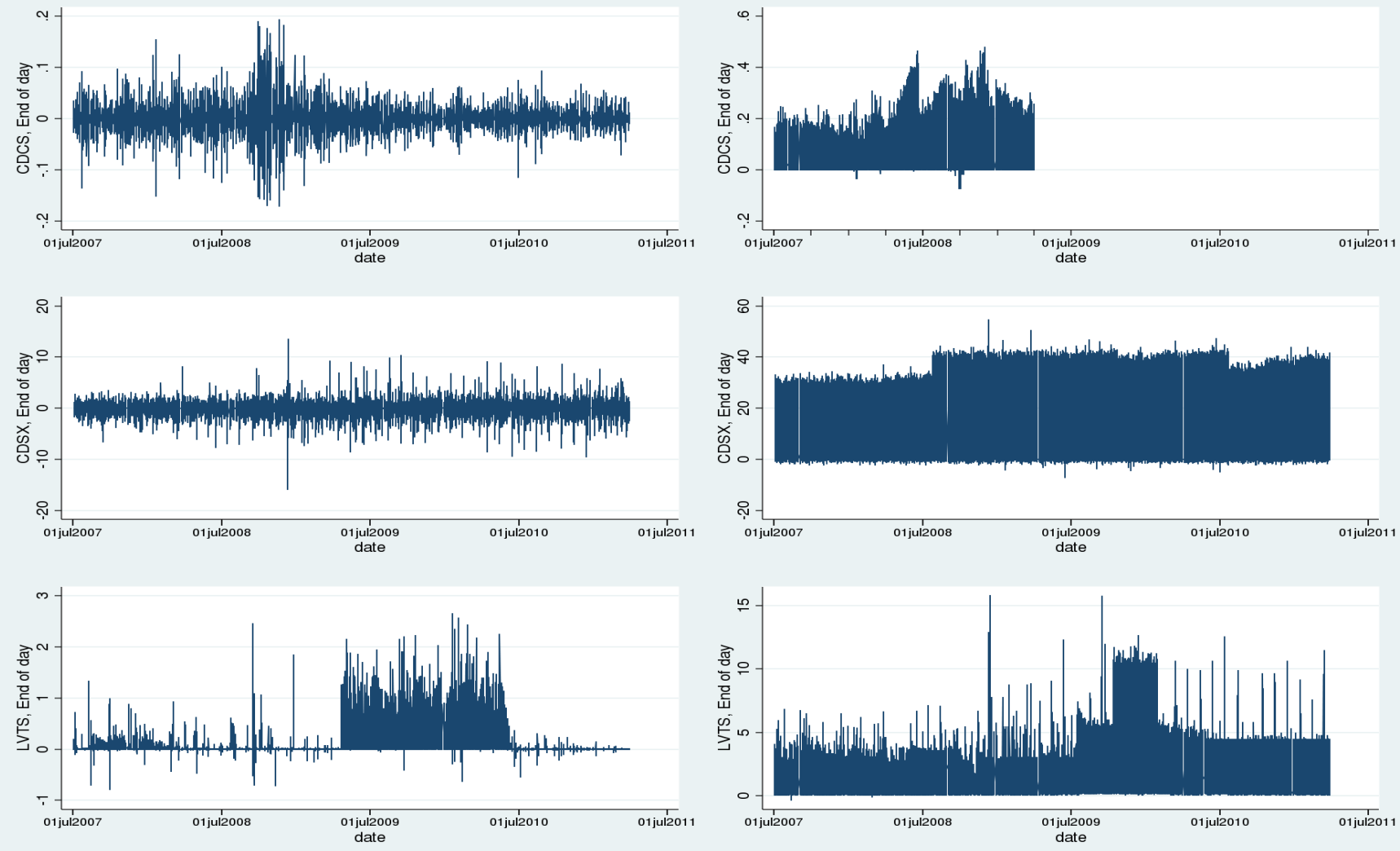